\title{
Partial Oxidation of Methane Over Co-ZSM-5: Tuning the Oxygenate Selectivity by Altering the Preparation Route
}

\author{
Nadzeya V. Beznis • Bert M. Weckhuysen • \\ Johannes H. Bitter
}

Received: 9 March 2009/ Accepted: 26 October 2009/Published online: 10 November 2009

(c) The Author(s) 2009. This article is published with open access at Springerlink.com

\begin{abstract}
For the first time the possibility to partially oxidize methane to methanol and formaldehyde at low temperature over Co-ZSM-5 using air is shown. The influence of the preparation method on the nature of the cobalt species is investigated. In addition, the catalytic activity and selectivity for methane oxidation as a function of the cobalt speciation is discussed. Based on UV-visNIR and FT-IR spectroscopy, $\mathrm{H}_{2}$-TPR, TEM and kinetic measurements it is concluded that cobalt in ion-exchange positions results mainly in the formation of formaldehyde, while larger Co-oxide particles prepared by impregnation result in the formation of methanol.
\end{abstract}

\section{Introduction}

The direct conversion of methane to methanol and formaldehyde holds one of the greatest challenges in heterogeneous catalysis [1-4]. Methane is an important fossil feedstock and its direct partial oxidation to oxygenates is challenging for thermodynamic reasons. Currently, oxygenates (e.g. methanol) are prepared from methane via a multi-step process. First syn-gas $\left(\mathrm{CO}\right.$ and $\left.\mathrm{H}_{2}\right)$ is generated followed by the oxygenate formation in a second step [5-7]. Though these processes are highly efficient, methanol synthesis following this route is only economically viable when performed on a large scale, which is the result of high capital costs for syn-gas production [8]. Obviously,

N. V. Beznis · B. M. Weckhuysen · J. H. Bitter $(\square)$ Inorganic Chemistry and Catalysis Group, Department of Chemistry, Debye Institute for Nanomaterials Science, Utrecht University, Sorbonnelaan 16, 3584 CA Utrecht, The Netherlands e-mail: j.h.bitter@uu.nl a more convenient way for small-scale methanol production would be the direct synthesis of methanol from methane making use of air or oxygen.

Fe-ZSM-5 is known to be active for this conversion although $\mathrm{N}_{2} \mathrm{O}$ was indispensable as oxidant [9, 10]. Due to the limited availability of $\mathrm{N}_{2} \mathrm{O}$ the use of molecular oxygen or air as an oxidant is more attractive. Recently, it was reported that $\mathrm{Cu}-\mathrm{ZSM}-5$ was able to perform the methane to methanol reaction. However, a preliminary calcination to introduce active oxygen is required. It is also necessary to mention here that the methanol formation is not continuous yet and an extraction procedure is needed [11, 12]. An initial screening study in our laboratory showed that especially Co-ZSM-5 displays intriguing catalytic behavior in the partial oxidation of methane to oxygenates. We will show in this work that Co-ZSM-5, preliminary calcined in air, can convert methane to methanol and/or formaldehyde.

Co-ZSM-5 can be prepared by different methods: wet ion-exchange [13-15], solid-state ion-exchange [16, 17], incipient wetness impregnation [14, 17] and sublimation [17]. The preparation method determines the cobalt species present in materials. Cobalt-loaded ZSM-5 samples may contain at least two cobalt species: $\mathrm{Co}^{2+}$ in ion-exchange position and cobalt oxidic species. These cobalt species exhibit different catalytic [18-20] and magnetic [14] properties.

We chose to prepare Co-ZSM-5 materials by wet ionexchange and incipient wetness impregnation. UV-visNIR Diffuse Reflectance (DR) spectroscopy, Fourier Transform Infrared Spectroscopy (FT-IR), Temperature Programmed Reduction $\left(\mathrm{H}_{2}\right.$-TPR $)$ and Transmission Electron Microscopy (TEM) were used to identify the nature of the Co-species present in these samples. The characterization results were related to the catalytic behavior of the samples in order to establish a qualitative 
structure-performance relation for the production of oxygenates over Co-ZSM-5 using methane and air.

\section{Experimental Part}

$\mathrm{NH}_{4}$-ZSM-5 (ZEOLYST, Si/Al = 17.5) was converted to Na-ZSM-5 via ion-exchange using $0.1 \mathrm{M} \mathrm{NaNO}_{3}(98 \%$, Acros Organics) at ambient temperature (RT) for $24 \mathrm{~h}$; the procedure was repeated three times. Ion-exchanged Co-ZSM5 catalysts were prepared using an aqueous solution of $0.02 \mathrm{M}$ cobalt acetate (98\%, Acros Organics) or cobalt nitrate (98\%, Acros Organics) for $24 \mathrm{~h}$. This procedure was performed both at RT and at $80^{\circ} \mathrm{C}$. After loading the samples were washed with demineralised water and dried at $120^{\circ} \mathrm{C}$ in static air. In addition, Co-ZSM-5 samples were also prepared by incipient wetness impregnation using either a $0.05 \mathrm{M}$ cobalt nitrate or acetate solution. After metal-loading the samples were dried at $60{ }^{\circ} \mathrm{C}$ in a flow of $\mathrm{N}_{2}$. The cobalt loading was determined by Atomic Absorption Spectroscopy (AAS).

For activation the samples were calcined at $550{ }^{\circ} \mathrm{C}$ for $3 \mathrm{~h}$ in flow of $\mathrm{N}_{2}(800 \mathrm{~mL} / \mathrm{min})$ and $\mathrm{O}_{2}(200 \mathrm{~mL} / \mathrm{min})$ with a ramp of $0.5^{\circ} \mathrm{C} / \mathrm{min}[21,22]$. After calcination the reaction with methane was performed (at $150{ }^{\circ} \mathrm{C}$ for $25 \mathrm{~min}$ in $8 \% \mathrm{CH}_{4}$ in He with total flow $25 \mathrm{~mL} / \mathrm{min}$ ) in a batch mode. Activation and reaction were performed in a quartz flow cell equipped with a UV-vis-NIR transparent window.

The analysis of the gas leaving the reactor was carried out using an Interscience Compact GC system, equipped with two different columns a Molsieve 5A and a Porabond $\mathrm{Q}$ columns each having a TCD detector.

After reaction with methane an extraction procedure was performed by stirring $0.2 \mathrm{~g}$ of the sample in $0.5 \mathrm{~mL}$ ethanol for $1 \mathrm{~h}$. A Shimadzu GC 2010 with CP-WAX 52 CB column and liquid sampler AOC-20i was used to quantify the product concentrations in the samples.

Both after calcination and after exposing to methane UV-vis-NIR Diffuse Reflectance (DR) spectra of the samples were recorded on a Varian Cary 500 spectrometer in the range $5,000-50,000 \mathrm{~cm}^{-1}(200-2,200 \mathrm{~nm})$. In order to eliminate the contributions of the zeolite material, a DR UV-vis-NIR spectrum of dehydrated ZSM-5 zeolite sample was subtracted of all Co-ZSM-5 samples.

The nature of surface species on the catalyst after exposing to methane was also investigated using Fourier Transform Infrared Spectroscopy (FT-IR). Samples, pressed into self-supporting wafers, were heated in $\mathrm{He}$ with a temperature ramp of $2{ }^{\circ} \mathrm{C} / \mathrm{min}$ to $200{ }^{\circ} \mathrm{C}$. Infrared spectra were recorded in a He flow at $200{ }^{\circ} \mathrm{C}$ on a Perkin Elmer FT-IR 2000 spectrometer using a DTGS detector. Twentyfive scans were averaged and data were baseline corrected and the intensity of each spectrum was normalized at the zeolite overtones $\left(1,850-1,950 \mathrm{~cm}^{-1}\right)$.
X-Ray Diffraction (XRD) patterns of the Co-ZSM-5 materials were recorded on a Nonius PDS 120 powder diffraction apparatus with $\mathrm{Co} \mathrm{K} \alpha$ radiation $(\lambda=1.78897 \AA)$.

For Transmission Electron Microscopy (TEM) measurements small amount of the sample was positioned on a carbon microgrid supported on copper. The microscope Tecnai 20 (FEI) equipped with a field emission gun was operated at $200 \mathrm{kV}$. Elemental composition was obtained by Energy Dispersive analysis of X-rays (EDX) performed through a LINK EDX system.

Temperature Programmed Reduction $\left(\mathrm{H}_{2}\right.$-TPR) was executed on an Autochem 2920 instrument from Micrometrics. $0.8 \mathrm{~g}$ catalyst was heated with a rate of $5{ }^{\circ} \mathrm{C} / \mathrm{min}$ in $5 \% \mathrm{H}_{2}$ in $\mathrm{Ar}(50 \mathrm{~mL} / \mathrm{min})$. Before the experiment the samples were dried in $\mathrm{Ar}$ at $120{ }^{\circ} \mathrm{C}$ for $1 \mathrm{~h}$.

\section{Results and Discussion}

Co-ZSM-5 (Si/Al-17.5) samples were prepared either by aqueous ion-exchange at RT or $80^{\circ} \mathrm{C}$, using either cobalt acetate or cobalt nitrate, or by incipient wetness impregnation also using an aqueous solution of cobalt nitrate or cobalt acetate (Table 1).

After drying the samples were in situ activated in air by a mild calcination procedure $[21,22]$ i.e., in a high gasflow rate $(1,000 \mathrm{~mL} / \mathrm{min})$ with a low temperature ramp $\left(0.5^{\circ} \mathrm{C} / \mathrm{min}\right)$. In that way the highest possible amount of moisture was removed at a relatively low temperature, while preventing metal ion clustering. The XRD patterns of all cobalt loaded ZSM-5 samples after calcination appeared to be identical, indicating no detectable damage of the ZSM-5 structure. No additional peaks due to the presence of cobalt oxide phases were found within the experimental sensitivity of XRD.

The nature of the cobalt species present can be visualized by means of UV-vis-NIR DR spectroscopy after calcinations and after reaction with methane. A UV-visNIR DR spectrum of calcined Co-IE_RT_A_0.9 is shown in Fig. 1A. Two triplet bands are visible. The first triplet is

Table 1 Overview of the samples under investigation, the sample loadings and their preparation method

\begin{tabular}{llll}
\hline Sample & Preparation & $\begin{array}{l}\text { Cobalt } \\
\text { precursor }\end{array}$ & $\begin{array}{l}\text { Co } \\
(\mathrm{wt} \%)^{\mathrm{a}}\end{array}$ \\
\hline Co_IE_RT_A_0.9 & Ion-exchange at RT & Cobalt acetate & 0.9 \\
Co_IE_RT_N_0.6 & Ion-exchange at RT & Cobalt nitrate & 0.6 \\
Co_IE_80_A_2.7 & Ion-exchange at $80{ }^{\circ} \mathrm{C}$ & Cobalt acetate & 2.7 \\
Co_IE_80_N_1.7 & Ion-exchange at $80{ }^{\circ} \mathrm{C}$ & Cobalt nitrate & 1.7 \\
Co_IMP_A_2.5 & Impregnation & Cobalt acetate & 2.5 \\
Co_IMP_N_2.5 & Impregnation & Cobalt nitrate & 2.5
\end{tabular}

${ }^{\text {a }}$ Determined by atomic absorbance spectroscopy 


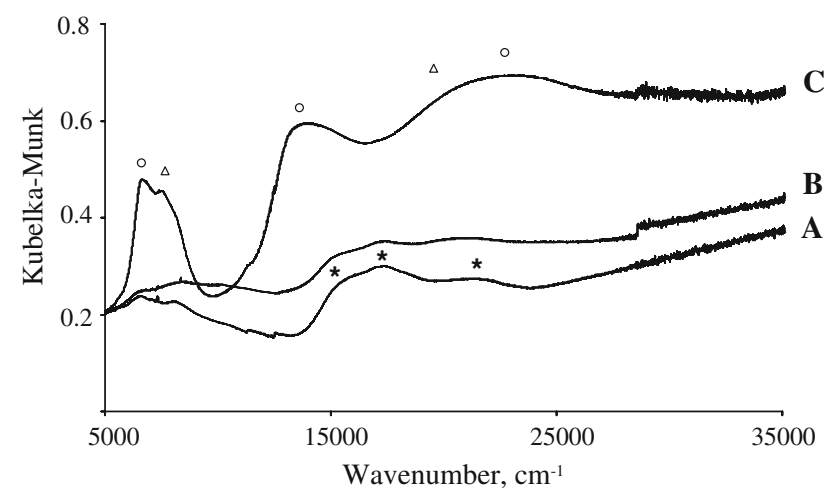

Fig. 1 The UV-vis-NIR DR spectra of Co_IE_RT_A_0.9 (A); Co_IE_80_A_2.7 $(B)$ and Co_IMP_N_2.5 $(C)$ after calcination at $550{ }^{\circ} \mathrm{C}$ (asterisk isolated $\mathrm{Co}^{2+}:{ }^{4} A_{2}(\mathrm{~F}) \rightarrow{ }^{4} T_{1}(\mathrm{P})$ transition; circle $\mathrm{Co}_{3} \mathrm{O}_{4}:{ }^{1} A_{1 g} \rightarrow{ }^{1} T_{2 g}$ and ${ }^{1} A_{1 g} \rightarrow{ }^{1} T_{1 g}$ transitions; triangle $\mathrm{CoO}:$ ${ }^{1} T_{1 g}(\mathrm{~F}) \rightarrow{ }^{1} T_{2 g}(\mathrm{~F})$ and ${ }^{1} T_{1 g}(\mathrm{~F}) \rightarrow{ }^{1} T_{1 g}(\mathrm{P})$ transitions $)$

in the near infrared (NIR) region $(5,000,6,500$ and $\left.8,000 \mathrm{~cm}^{-1}\right)$. This triplet could be assigned to the ${ }^{4} A_{2}(\mathrm{~F}) \rightarrow{ }^{4} T_{1}(\mathrm{~F})$ transition [23]. However, in the NIR region, the cobalt spectra might be overlapped by the overtone bands of $\mathrm{OH}$ groups $\left(7,200-7,400 \mathrm{~cm}^{-1}\right)$ and water molecules $\left(5,200 \mathrm{~cm}^{-1}\right)$. Therefore, the NIR region is usually used to check the dehydration of zeolites, while the vis region is used to monitor the nature of the cobalt species [13]. The second triplet (marked with asterisk) is observed in the visible region $(15,000,17,000$ and $21,500 \mathrm{~cm}^{-1}$ ) and is ascribed to the ${ }^{4} A_{2}(\mathrm{~F}) \rightarrow{ }^{4} T_{1}(\mathrm{P})$ transition [23]. Wichterlová et al. [13, 24] assigned the bands in the visible range to $\mathrm{Co}^{2+}$ located at three different sites in the ZSM-5, i.e., $\alpha$-, $\beta$ - and $\gamma$-sites, respectively. The UV-vis-NIR DR spectrum of Co_IE-RT_N_0.6 is identical to Co_IE_RT_A_0.9 and is therefore not shown.

A UV-vis-NIR DR spectrum of Co_IMP_N_2.5 is displayed in Fig. 1C. The broad band between 18,000 and $26,000 \mathrm{~cm}^{-1}$ and the band around $13,500 \mathrm{~cm}^{-1}$ (marked with circles) are indicative for $\mathrm{Co}_{3} \mathrm{O}_{4}$ clusters and they are ascribed to octahedral $\mathrm{Co}^{3+}\left({ }^{1} A_{1 \mathrm{~g}} \rightarrow{ }^{1} T_{2 \mathrm{~g}}\right.$ and ${ }^{1} A_{1 \mathrm{~g}} \rightarrow{ }^{1} T_{1 \mathrm{~g}}$ transitions) [25-27]. The band at $8,000 \mathrm{~cm}^{-1}$ and the band at around $19,600 \mathrm{~cm}^{-1}$ (marked with triangles) are ascribed to the ${ }^{1} T_{1 g}(\mathrm{~F}) \rightarrow{ }^{1} T_{2 g}(\mathrm{~F})$ and ${ }^{1} T_{1 g}(\mathrm{~F}) \rightarrow{ }^{1} T_{1 g}(\mathrm{P})$ respectively and indicate the presence of $\mathrm{CoO}$ [28]. Therefore, it is concluded that samples prepared by aqueous impregnation contain mainly cobalt oxide species, both
$\mathrm{CoO}$ and $\mathrm{Co}_{3} \mathrm{O}_{4}$. Similar observations were made by impregnation, using cobalt acetate as a precursor.

The samples prepared by ion-exchange at $80{ }^{\circ} \mathrm{C}$ have higher metal loadings (2.7 and $1.7 \mathrm{wt} \%$, using cobalt acetate and cobalt nitrate, respectively) in comparison with the samples prepared by ion-exchange at RT ( 0.9 and $0.6 \mathrm{wt} \%$, using cobalt acetate and cobalt nitrate, respectively) (Table 1). Figure 1B shows a UV-vis-NIR DR spectrum of Co_IE_80_A_2.7. Three bands at 15,000, 17,000 and $21,500 \mathrm{~cm}^{-1}$ indicate the presence of $\mathrm{Co}^{2+}$ in ion-exchange position as discussed above. In addition the broad between 18,000 and $26,000 \mathrm{~cm}^{-1}$ indicate the presence of $\mathrm{Co}_{3} \mathrm{O}_{4}$. Co_IE_80_N_1.7 also showed the formation of both species.

To give a quantification of the different Co-species present in the samples $\mathrm{H}_{2}$-TPR measurements were performed. Based on the literature, three regions of reduction can be expected, i.e., below $400{ }^{\circ} \mathrm{C}$ representing the reduction of extraframework bulk-like $\mathrm{Co}_{3} \mathrm{O}_{4}$ particles; between 400 and $700{ }^{\circ} \mathrm{C}$ representing the reduction of intraframework $\left(\mathrm{CoO}_{x}\right)_{n}$ oligomers containing $\mathrm{Co}^{2+}$; and peaks between 700 and $900{ }^{\circ} \mathrm{C}$ representing the reduction of extraframework cobalt (II) phyllosilicate (Table 2). Isolated $\mathrm{Co}^{2+}$ can only be reduced above $900{ }^{\circ} \mathrm{C}$. Their quantity was, in general, calculated by the difference between the total amount of cobalt and the amount of cobalt quantified based on the thermograms [29-31].

Table 2 presents the quantification of cobalt species using $\mathrm{H}_{2}$-TPR analysis. For the Co_IE_RT_A_0.9 sample isolated $\mathrm{Co}^{2+}$ are the main cobalt species $(80 \%)$, which is in a good agreement with the UV-vis-NIR DR data. For Co_IMP_N_2.5 we observed mainly cobalt oxide species (85\%). Co_IE_80_A_2.7 is an intermediate case and showed $25 \%$ of Co-oxide species, $50 \%$ isolated $\mathrm{Co}^{2+}$ and $25 \%$ cobalt phyllosilicate.

The $\mathrm{H}_{2}$-TPR results confirmed UV-vis-NIR DR results and also give the quantification of cobalt species present in Co-ZSM-5 materials.

These findings are also supported by TEM, as indicated in Fig. 2. For Co_IE_RT_A_0.9 (Fig. 2a) no cobalt-containing particles on the outer surface of the zeolite could be found. An EDX analysis confirmed the presence of cobalt throughout the sample suggesting that most cobalt was distributed inside the ZSM-5 channels. Please note that prolonged exposure (few minutes) of the samples resulted

Table $2 \mathrm{H}_{2}$-TPR results of Co-ZSM-5 samples prepared by different methods

\begin{tabular}{llllllll}
\hline Sample & $T_{1 \max }\left({ }^{\circ} \mathrm{C}\right)$ & $T_{2 \max }\left({ }^{\circ} \mathrm{C}\right)$ & $T_{3 \max }\left({ }^{\circ} \mathrm{C}\right)$ & $\% \mathrm{Co}^{x+}$ in $\mathrm{Co}_{3} \mathrm{O}_{4}\left(T_{1}\right)$ & $\% \mathrm{Co}^{2+}$ in $\mathrm{CoO}\left(T_{2}\right)$ & $\% \mathrm{CoSiO}_{4}\left(T_{3}\right)$ & $\% \mathrm{Isolated} \mathrm{Co}^{2+}$ \\
\hline Co_IE_RT_A_0.9 & 360 & 690 & - & 10 & 10 & - & 80 \\
Co_IE_80_A_2.7 & 350 & 670 & 805 & 10 & 15 & 25 & 50 \\
Co_IMP_N_2.5 & 325 & 700 & - & 35 & 50 & - & 15 \\
\hline
\end{tabular}


Fig. 2 TEM micrographs of Co_IE_RT_A_0.9 (a), Co_IE_80_A_2.7 (b) and Co_IMP_N_2.5 (c) (cobalt oxide particles are encircled)
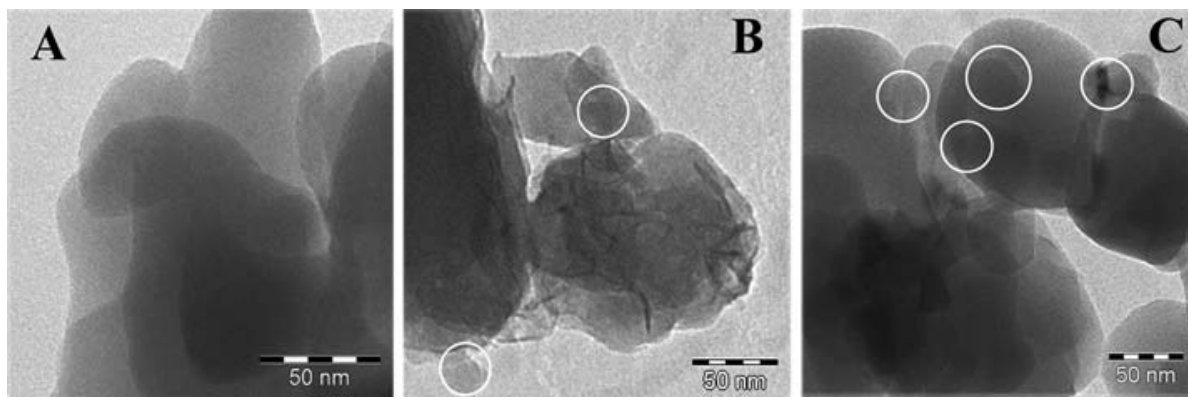

in large cobalt-containing particles $(2-5 \mathrm{~nm})$ most likely as the result of Co migration and sintering from the pores to the external surface.

Figure 2b, c show TEM images of Co_IE_80_A_2.7 and Co_IMP_N_2.5, respectively. Large cobalt oxide particles $(10-50 \mathrm{~nm})$ were observed for both samples. Areas, where no particles were visible, were also present.

In case of Co_IE_80_A_2.7 cobalt species in needle like structures were observed. This gives an additional confirmation of the presence of cobalt silicate in that sample [30, 32].

To check the catalytic activity after calcination the activated samples were exposed to methane $\left(8 \% \mathrm{CH}_{4}\right.$ in $\mathrm{He}$ at $150{ }^{\circ} \mathrm{C}$ for $25 \mathrm{~min}$ ). The gas phase was analyzed during the experiments and indicated that no gaseous products were formed. It is necessary to mention that UV-vis-NIR DR spectra of all prepared Co-ZSM-5 materials after exposure to methane did not show significant difference as compared to the activated sample.

Since the products of the reaction strongly adsorb on the surface of the catalyst an extraction procedure is needed to evaluate the catalytic activity of the samples. The extraction was performed with ethanol. GC analyses were performed to check the amount of formed products.

Figure 3 summarize the catalytic activity and selectivity of the different Co-ZSM-5 samples under investigation. The Co_IE_RT_N_0.6 sample was not active for methane oxidation for unknown reasons. However, Co_IE_RT_A_0.9 with $80 \%$ isolated $\mathrm{Co}^{2+}$ shows the formation of two products: methanol and formaldehyde, with $75 \%$ selectivity towards formaldehyde. Samples prepared by impregnation, using either cobalt acetate or cobalt nitrate as metal precursor, i.e., possessing $85 \%$ of the cobalt as oxidic species, were $100 \%$ selective towards methanol.

Cobalt samples prepared by ion-exchange at $80{ }^{\circ} \mathrm{C}$ (Co_IE_80_A_2.7 and Co_IE_80_N_1.7), having both oxidic Co-species and isolated $\mathrm{Co}^{2+}$ species, show the formation of both products: methanol and formaldehyde. Co_IE_80_N_1.7 was $40 \%$ selective towards methanol and $60 \%$ selective towards formaldehyde, which is similar to that of Co_IE_80_A_2.7 (45\% methanol and 55\% formaldehyde).

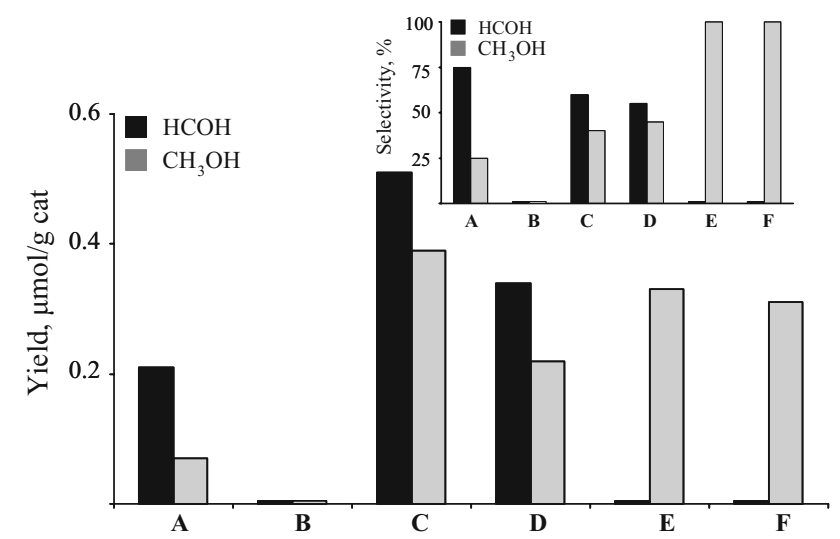

Fig. 3 Catalytic activity and selectivity (insert) of Co-ZSM-5 samples for methane oxidation to oxygenates: Co_IE_RT_A_0.9 $(A)$; Co_IE_RT_N_0.6 (B); Co_IE_80_A_2.7 (C); Co_IE_80_N_1.7 $(D)$; Co_IMP_N_2.5 $(E)$ and Co_IMP_A_2.5 $(F)$

In addition, it should be mentioned here that it is possible to regenerate the catalyst. After extraction in ethanol the Co-ZSM-5 materials were dried and calcined in air as described above and reused in a second cycle. Similar activities were observed as in previous run.

As it was discussed above, the products of the reaction strongly adsorb on the surface of the catalyst. Thus, we speculate that the strongly adsorbed species are methoxy species. It is known that the formation of a methoxy species $\left(-\mathrm{OCH}_{3}\right)$ is generally considered as one of the first steps in chemisorption of methane on an oxidic surface [33, 34]. The formation of methoxy species was indeed confirmed by FT-IR measurements (Fig. 4). Vibrations at around 2,950 and $2,980 \mathrm{~cm}^{-1}$ are related to asymmetric $\mathrm{CH}$ stretching modes. Symmetric $\mathrm{CH}$ stretching vibration were found around $2,850 \mathrm{~cm}^{-1}[42,43]$, and the band at $2,980 \mathrm{~cm}^{-1}$ is related to a center rotational band. The positions of the bands were similar for all Co-ZSM-5 samples.

Thus, by relating the catalytic results with UV-vis, $\mathrm{H}_{2}-$ TPR and TEM data we can summarize that the sample which only contained monoatomic $\mathrm{Co}^{2+}$ in ion-exchanged positions (Co_IE_RT_A_0.9) is the most selective towards formaldehyde formation. By increasing the amount of 


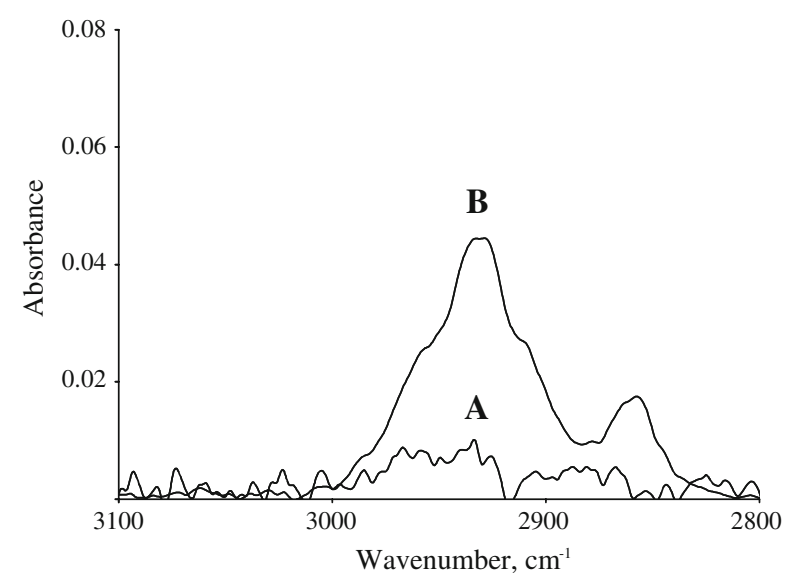

Fig. 4 FT-IR spectra of Co_IE_80_A_2.7 in a He flow at $200{ }^{\circ} \mathrm{C}$ before reaction with methane $(A)$ and after exposure to methane $(B)$

oxidic cobalt species i.e., samples prepared either by ionexchange at $80{ }^{\circ} \mathrm{C}$ or by impregnation, the selectivity towards methanol increased thus indicating that the presence of oxidic cobalt species relate to the semi qualitative methanol production.

\section{Conclusions}

Co-ZSM-5 samples are able to partially oxidize methane to oxygenates in one step at low temperature using air as an oxidant. Using different preparation methods it is possible to tune the catalytic activity and selectivity of the catalytic system. In the samples prepared by ion-exchange at RT most cobalt was found to be in ion-exchange positions. These samples were most selective towards formaldehyde. Instead, impregnated samples, containing mainly oxidic cobalt species $\left(\mathrm{CoO}\right.$ and $\left.\mathrm{Co}_{3} \mathrm{O}_{4}\right)$, are more selective towards methanol.

Acknowledgments Financial support was provided by ACTSASPECT (Project 053.62.006).

Open Access This article is distributed under the terms of the Creative Commons Attribution Noncommercial License which permits any noncommercial use, distribution, and reproduction in any medium, provided the original author(s) and source are credited.

\section{References}

1. Periana RA, Taube DJ, Evitt ER, Löffler DG, Wentreck PR, Voss G, Masuda T (1993) Science 259:340

2. Liu H-F, Liu R-S, Liew KY, Johnson RE, Lunsford JH (1984) J Am Chem Soc 106:4117
3. Li F, Yuan G (2005) Chem Commun 17:2238

4. Bar-Nahum I, Khenkin AM, Neumann R (2004) J Am Chem Soc 126:10236

5. Osako T, Watson EJ, Dehestani A, Bales BC, Mayer JM (2006) Angew Chem Int Ed 45:7433

6. Bañares MA, Cardoso JH, Hutchings GJ, Correa Bueno JM, Fierro JLG (1998) Catal Lett 56:149

7. Liu Z-P, Hu P (2002) J Am Chem Soc 124:11568

8. Poels EK, Brands DS (2000) Appl Catal A Gen 191:83

9. Sobolev VI, Dubkov KA, Panna OV, Panov GI (1995) Catal Today 24:251

10. Panov GI, Kharitonov AS, Sobolev VI (1993) Appl Catal 98:1

11. Groothaert MH, Smeets PJ, Sels BF, Jacobs PA, Schoonheydt RA (2005) J Am Chem Soc 127:1394

12. Smeets PJ, Groothaert MH, Schoonheydt RA (2005) Catal Today 110:303

13. Dědeček J, Kaucký D, Wichterlová B (2000) Micropor Mesopor Mater 35-36:483

14. Pierella LB, Saux C, Caglieri SC, Bertorello HR, Bercoff PG (2008) Appl Catal A Gen 347:55

15. Montanari T, Bevilacqua M, Resini C, Busca G, Pirone R, Ruoppolo G (2007) J Porous Mater 14:291

16. da Cruz RS, Macarenhas AJS, Andrade HMC (1998) Appl Catal B Environ 18:223

17. Wang X, Chen H, Sachtler WMH (2000) Appl Catal B Environ 26:L227

18. Lee C, Chong P, Lee Y, Chin C, Kevan L (1997) Micropor Mater 12:21

19. Moreno-Tost R, Santamaría-Gonzales J, Maireles-Torres P, Rodriquez-Castellón E, Jimenez-López A (2002) Appl Catal B Environ 38:51

20. Bulánek R, Novoveská K, Wichterlová B (2002) Appl Catal A Gen 235:181

21. Battiston AA, Bitter JH, de Groot FMF, Overweg AR, Stephan O, van Bokhoven JA, Kooyman PJ, van der Spek C, Vanko G, Koningsberger DC (2003) J Catal 213:251

22. de Graaf J, van Dillen AJ, de Jong KP, Koningsberger DC (2001) J Catal 203:307

23. Verberckmoes AA, Weckhuysen BM, Schoonheydt RA (1998) Micropor Mesopor Mater 22:165

24. Kaucký D, Dědeček J, Wichterlová B (1999) Micropor Mesopor Mater 31:75

25. Vakros J, Kordulis C, Lycourghiotis A (2002) Langmuir 18:417

26. Liotta LF, Pantaleo G, Macaluso A, Di Carlo G, Deganello G (2003) Appl Catal A Gen 245:167

27. van de Water LGA, Bezemer GL, Bergwerff JA, Versluijs-Helder M, Weckhuysen BM, de Jong KP (2006) J Catal 242:287

28. lever ABP (1984) Inorganic electronic spectroscopy, 2nd edn. Elsevier, Amsterdam

29. Boubaker HB, Mhamdi M, Marceau E, Khaddar-Zine S, Ghorbel A, Che M, Taarit YB, Villain F (2006) Micropor Mesopor Mater 92:62

30. Mhamdi M, Marceau E, Khaddar-Zine S, Ghorbel A, Che M, Taarit YB, Villain F (2004) Catal Lett 98:135

31. de Cruz RS, Mascarenhas AJS, Andrade HMC (1998) Appl Catal B 18:223

32. Chupin C, van Veen AC, Konduru M, Després J, Mirodatos C (2006) J Catal 241:103

33. Finocchio E, Busca G, Lorenzelli V, Willey RJ (2001) J Catal 151:204

34. Steghuis AG, van Ommen JG, Seshan K, Lercher JA (1997) Stud Surf Sci Catal 107:403 